\title{
Chemokines in Inflammatory Bowel Diseases
}

\author{
Raja Atreya M.F. Neurath \\ Medical Clinic 1, University of Erlangen-Nuremberg, Erlangen, Germany
}

\section{Key Words}

Chemokine receptors $\cdot$ Chemokines $\cdot$ Inflammatory bowel diseases

\begin{abstract}
Uncontrolled activation of mucosal effector cells has been identified as the main pathogenic mechanism involved in the initiation and perpetuation of mucosal inflammation in inflammatory bowel diseases (IBD). The sustained activation of these cells leads to the aberrant production of various proinflammatory mediators, which co-ordinated action amplifies the inflammatory process. In this setting a network of tissue-specific chemoattractant cytokines (chemokines) and their corresponding receptors have been implicated as main contributors in the initiation and perpetuation of the inflammatory reaction in IBD. They are produced by a variety of inflammatory cells present in IBD lesions, as well as endothelial and epithelial cells. Chemokines not only control the multistep process of leukocyte adhesion to and migration across the endothelium, but also the release of lipid mediators and oxygen radicals from leukocytes, the modulation of tumorigenesis, release of matrix metalloproteinases and tissue fibrosis. Numerous data indicate that that intestinal chemokine expression is non-selectively up-regulated in IBD and correlates with disease activity. The development of selec-
\end{abstract}

tive inhibitors for chemokines or chemokine receptors, based on a more complete understanding of the immunopathogenic role of chemokines in intestinal inflammation, will be of great interest as potential novel therapeutic strategies in IBD.

Copyright $\odot 2010$ S. Karger AG, Basel

\section{Immunopathogenesis of Inflammatory Bowel Diseases}

Crohn's disease and ulcerative colitis are the two major forms of inflammatory bowel diseases (IBD), which are defined as chronically relapsing inflammatory conditions of the gastrointestinal tract not resulting from specific pathogens. Whereas Crohn's disease is a segmental, transmural disorder involving any part of the gastrointestinal tract, ulcerative colitis is characterized by continuous inflammation involving the mucosa and submucosa of the large intestine. Both entities are characterized by an unpredictable disease course that may lead to debilitating complications, including an increased incidence of colorectal cancer [1].

Although the precise etiology of IBD still remains obscure, there is a general consensus that a disturbed interaction of enteric antigens with the intestinal immune sys-

\section{KARGER \\ Fax +41613061234 \\ E-Mail karger@karger.ch}

www.karger.com
(C) 2010 S. Karger AG, Basel

0257-2753/10/0283-0386\$26.00/0

Accessible online at:

www.karger.com/ddi
Raja Atreya

Ulmenweg 18

DE-91054 Erlangen (Germany)

Tel. +499131853 500, Fax +496131 175508

E-Mail raja.atreya@uk-erlangen.de 
tem of a genetically susceptible host greatly contributes to disease pathogenesis. This leads to the disruption of mucosal homeostasis and excessive activation of the mucosal immune system. Advances in the past few years have elucidated some of the underlying immunopathogenic mechanisms involved in the inflammatory process [2-5].

While the normal intestinal immune system is under a carefully controlled regulatory balance that maintains a state of equilibrium in spite of its constant encounter with commensal and pathogenic antigens, IBD is characterized by a malfunction of these immune-regulatory mechanisms [6]. Uncontrolled activation of mucosal effector cells has been identified as the main pathogenic mechanism involved in the initiation and perpetuation of the intestinal inflammatory reaction $[7,8]$. The sustained activation of these cells leads to the aberrant production of various pro-inflammatory mediators, co-ordinated action of which amplifies the inflammatory process $[9$, 10].

Among the network of pro-inflammatory mediators involved in IBD pathogenesis, special attention has been paid to cytokines and chemokines, which are small (4$15 \mathrm{kDa}$ ) inducible immune-regulatory proteins that play a central role in the development and homeostasis of the immune system [11]. The pathogenic position of pro-inflammatory cytokines in IBD has long been the focus of extensive research. Alterations in the mucosal cytokine profile, resulting in an imbalance between pro- and antiinflammatory cytokines, have been demonstrated for both Crohn's disease and ulcerative colitis [12]. It is generally believed that intestinal macrophages and especially CD4+ T lymphocytes play a crucial role in the cytokine-driven inflammation underlying these diseases. The $\mathrm{T}$ helper cells have been classified as Th1, Th2 or Th17 cells, according to their cytokine profile [13]. This aggressive $\mathrm{T}$ effector cell activation is insufficiently counteracted by regulatory and anti-inflammatory $\mathrm{T}$ cells (Treg, Tr1 and Th3), thereby leading to the inflammatory reaction [7].

Crohn's disease is characterized by CD4+ lymphocytes with a predominant Th1 [12] and TH17 phenotype [14]. Excessive IL-12/IL-23 and IFN- $\gamma /$ IL-17 production determine the downstream release of further pro-inflammatory cytokines in Crohn's disease. Mucosal immune response in ulcerative colitis differs from this, as it is marked by a Th17 and a modified Th2 phenotype, with excessive production of IL-13 and IL-5, but not IL-4. In addition, disease-perpetuating cytokines like IL- 6 and TNF- $\alpha$ are produced by both Th1 and Th 2 cells as well as by macrophages in both IBD entities $[2,15]$.

Chemokines in Inflammatory Bowel Diseases
The final result of this intricate cytokine network is the recruitment of more effector cells and induction of tissue-damaging (nitric oxide, prostacylin) and other inflammatory mediators (leukotriens and prostaglandins), which further amplify mucosal inflammation [16]. Inflammatory mediators therefore present potentially attractive therapeutic targets to establish novel treatment options for patients with IBD. The possible impact of such an approach is best provided by the advent of anti-TNF antibodies, which have by now become an integral part of the therapeutic options in IBD [17-20].

Other critical determinants of mucosal inflammation in IBD are chemoattractant cytokines (chemokines) and their corresponding receptors, which play a key participatory role in the inappropriate recruitment and accumulation of leukocytes into the pathologically inflamed gut [21]. This constant influx of leukocytes leads to further exacerbation of destructive processes within the intestine. Histologically, neutrophil migration is characteristic for chronic intestinal inflammation and the level of active inflammation refers to the presence of extra-vascular neutrophils, correlating with clinical disease activity in IBD [22]. The final composition of leukocytes and also macrophages and granulocytes from circulation into the mucosa is determined by the relative expression of the various chemokines and their specific cell surface receptors, which thereby play a decisive role in the perpetuation of mucosal inflammation $[23,24]$. Apart from aberrant leukocyte chemoattraction, chemokines also orchestrate production of metalloproteinases for matrix degradation, granule exocytosis and up-regulation of the oxidative burst, which all contribute to chronic intestinal inflammation and mucosal destruction (fig. 1). In the following, the inflammatory role of chemokines in the immunopathogenesis of IBD is discussed with extension to their potential as molecular targets for therapeutic intervention.

\section{Chemokines}

Chemokines are a large family of small $(7-15 \mathrm{kDa})$ structurally related heparin-binding proteins with wellrecognized roles in adhesion and directional homing of immune and inflammatory cells. Over 40 chemokines have been identified so far and have been divided into four subfamilies (C, CC, CXC and CXC3) based on the arrangement of cysteine residues in the amino-terminus of the protein. The major subgroups consist of CXC chemokines (largely involved in neutrophil and monocyte 
Fig. 1. The immunopathogenic role of chemokines in IBD. Chemokines and their corresponding receptors contribute to the intestinal inflammatory process in IBD. They control the multistep process of the migration of effector immune cells across the endothelium, modulate the release of lipid mediators and oxygen radicals from leukocytes, regulate the production of metalloproteinases and matrix degradation, influence tissue fibrosis and participate in the process of tumorigenesis. LPMCs = Lamina propria mononuclear cells.

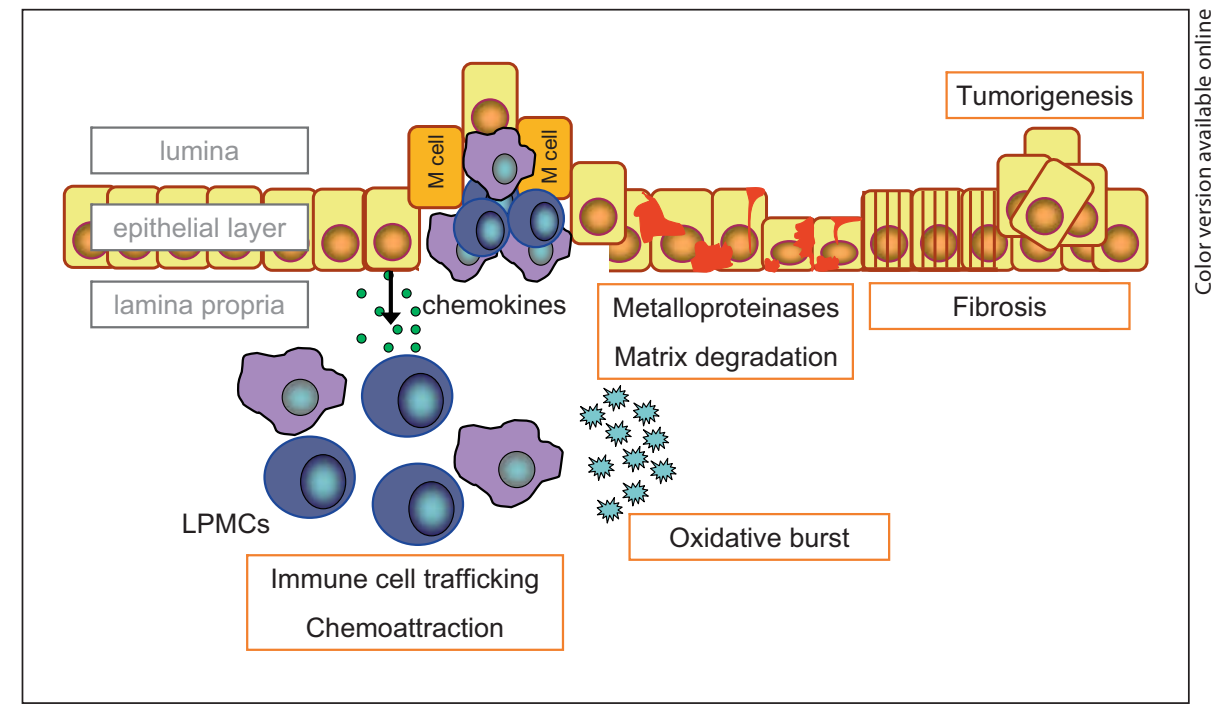

recruitment) and CC chemokines (more strongly implicated in lymphocyte and dendritic cell recruitment) [25, 26]. Functionally chemokines are classified into two groups: 'constitutively secreted' and 'inducible' [27]. The homeostatic or constitutive subfamily plays an important immune surveillance role in basal leukocyte trafficking into or within lymphoid organs and peripheral tissue, as well as organization of lymphoid tissue. They are expressed in thymus, secondary lymphoid organs and extra-lymphoid tissues. Inducible chemokines on the other hand are secreted by infiltrating leukocytes and tissue cells upon stimulation with pro-inflammatory cytokines (e.g. TNF- $\alpha$, IFN- $\gamma$ ) and are responsible for the chemoattractant gradient that directs effector leukocytes to the site of inflammation [27].

Chemokines exert their biological effect by interacting with specific G-protein coupled receptors on target cells. This characteristically leads to an increased flux in intracellular calcium and, in turn, chemotactic migration of those cells [25]. Redundancy of ligand for chemokine receptor is a characteristic hallmark of this protein family. Thus, several chemokines are able to bind to more than one receptor, whereas few receptors bind a single ligand. This leads to a high level of redundancy in chemokine receptor function, especially in inflammatory responses $[21,25]$.

Chemokines not only control the multistep process of leukocyte adhesion to and migration across the endothelium, but also modulate angiogenesis, tissue development, tumor metastasis, tissue fibrosis, epithelial wound healing and release of lipid mediators and oxygen radicals from leukocytes $[28,29]$.

The notion that chemokines and their receptors might contribute to the immunopathogenesis of IBD stems from a series of clinical studies published nearly twenty years ago, where an increased expression of CXCL8/IL-8 was found in rectal biopsies of IBD patients [30-32]. In the following years considerable progress has been made in understanding the functional role of chemokines in the mechanisms of inflammation in IBD.

\section{CXCL8 and CXCR1}

Among CXC chemokines, the role of CXCL8 (IL-8) has been intensively studied. It could reproducibly be shown that CXCL-8 production is significantly increased in mucosal samples from ulcerative colitis as well as Crohn's disease patients in comparison to respective controls [30-32]. Consistent with these findings is data that shows increased expression of CXCR1, the corresponding receptor for CXCL-8, in the colon of IBD patients [33]. Subsequent studies also demonstrated that expression of CXCL-8 closely correlated with the severity of inflammation $[31,34,35]$. Moreover, these studies also favor the observation that clinically and histologically inactive segments of the bowel also express raised CXCL-8 levels, indicating that even in quiescent disease the mucosa is not completely inert but shows signs of disease [36-39]. 
There was also a striking correlation between colonic mucosal CXCL- 8 expression and IL- $1 \beta$ and TNF- $\alpha$ levels [35]. It could also be shown that this chemokine accounts for the leukocyte chemotactic activity in the inflamed colon. The precise cell types which produce CXCL-8 during active disease have been the subject of a number of investigations. It was reproducibly shown that neutrophils, macrophages, fibroblasts and intestinal epithelial cells account for CXCL- 8 production at the sites of active Crohn's disease and ulcerative colitis [36]. Taken together, these studies demonstrate the possible involvement of CXCL-8 in the immunopathogenesis of IBD, which may also be reflected by observations that steroid treatment in IBD patients results in decreased expression of this important chemokine [40]. Therefore CXCL-8 might represent an attractive target for new therapeutic approaches in IBD. This therapeutic strategy is already under investigation in clinical trials with humanized monoclonal antibodies against the IL- 8 receptor CXCR2 in the treatment of chronic obstructive pulmonary disease (COPD) [41].

\section{CXCL9, CXCL10, CXCL11 and CXCR3}

The chemokine receptor CXCR3 is expressed by epithelial, endothelial and lymphoid cells [42]. Its ligands CXCL 9 (MIG), CXCL10 (IP-10) and CXCL11 (I-TACH) are induced by IFN- $\gamma$ and attract Th1 cells expressing high levels of CXCR3 [43]. It has also been reported that CXCL10 inhibits intestinal epithelial cell proliferation and regulates crypt cell proliferation during acute colitis [44]. CXCL9-11 also enable NK cell chemotaxis and augment NK cell specific cytolytic response [45].

Increased expression of CXCR3, especially in CD4+ $\mathrm{T}$ lymphocytes, could be demonstrated in the mucosa of IBD patients compared to controls [46]. In vitro experiments also revealed a heightened expression of the CXCR3 in intestinal epithelial cells upon stimulation with various pro-inflammatory cytokines. In confirmation, CXCL9-11 are also up-regulated at the sites of active colitis [47]. Moreover CXCL10 expression has been shown to be heightened in the mucosa of patients with ulcerative colitis and Crohn's disease as well [48]. Correspondingly, CXCL9-11 serum levels in IBD patients are increased as well $[49,50]$.

Interestingly in IL 10-/- mouse (an experimental colitis model) treatment with an anti-CXCL10 antibody could abrogate spontaneous colitis, which coincided with a significant decrease of the pro-inflammatory cytokines
IL-6, TNF- $\alpha$ and also IFN- $\gamma$ [50]. In addition in the dextran sodium sulfate (DSS)-induced colitis model, the neutralization of CXCL10 protected mice from colitis and intestinal ulcerations by enhancing crypt cell survival [51].

Consequently phase one clinical trials with a fully human anti-CXCL10 monoclonal antibody (MDX-1100) have been initiated in the treatment of IBD patients.

\section{CCL2 and CCR2}

The chemokine CCL2 (MCP-1), which only uses CCR2 as its single receptor, has potent chemotactic and activating activities for monocytes and macrophages [52]. Several studies identified elevated CCL2 mRNA and protein expression in the mucosa of IBD patients $[53,54]$. Strikingly, only CD4+ T cells in ileal Crohn's disease, but not those infiltrating the colon, exhibit increased CCR2 expression, reflecting the regional variation of chemokine expression [55]. In the DSS-induced colitis model, CCR2 deficient mice exhibited reduced signs of colitis [56] and combined blockade of CCR2, CCR 5 and CXCR3 protected these mice from the onset of colitis along with a reduction regarding intestinal infiltration with $\mathrm{CD} 11 \mathrm{~b}+$ macrophages [57]. This reduction could also be achieved in this colitis model by the application of distinct CCL2 antagonists. Moreover, in the azoxymethane-DSS (AOMDSS) model, which mimics colitis-associated colon carcinogenesis, CCL2 expression was enhanced together with massive macrophage infiltration. Mice deficient for CCR 2 concordantly exhibited decreased macrophage infiltration and lower tumor numbers and application of a CCL2 antagonist also reduced the size and numbers of colon tumors in this model [58]. These observations thereby identify CCL2/CCR2 not only as crucial mediators in intestinal inflammation but also in the initiation and progression of colitis associated colon cancer. Therefore targeting the CCL2/CCR2 interaction may be useful in the treatment of gut inflammation and even inflammation-associated colon cancer.

Intriguingly, a recently published study indicates that CCL2 does not necessarily only augment the inflammatory process, but can also exert anti-inflammatory effects when administered in sub-physiological doses by inhibiting the migration of $\mathrm{T}$ cells in experimental colitis models. Furthermore, low-dose CCL2 also prevented the onset of inflammation-enhanced carcinoma in the AOMDSS model [59]. Further research is definitely needed to fully analyze theses effects. 


\section{CCL5, CCL6 and CCR1, CCR5}

The chemokine CCL5 (RANTES) is also expressed in the inflamed gut of Crohn's disease patients [53]. In further experiments increased colonic expression of CCL5 and its receptors CCR 1 and CCR5 in TNBS-induced colitis were associated with augmented migration of inflammatory cells into colonic tissue and the appearance of ulcerative lesions. These results suggest that CCL5 attracts CCR 1 and CCR 5 expressing cells into the mucosa, where activation of these cells leads to tissue destruction [6062]. In other murine studies, CCR5-deficient mice exhibited a reduction of intestinal inflammation during DSSmediated colitis when compared to respective wild-type controls [56].

The chemokine receptor CCR5 is predominantly expressed in Th1 lymphocytes in Crohns's disease [57], but can also be detected on regulatory $\mathrm{T}$ cells as well. This dual expression enables the recruitment of pro- or antiinflammatory cells to the tissue. This is visible in SAMP/ Yit mice, where the induction of CCL5 leads to the recruitment of FoxP3+ regulatory $\mathrm{T}$ cells into the inflamed mucosa $[63,64]$.

An increase in the expression of the chemokine CCL6 (MCP-3) has also been also reported in colonic biopsies of patients with active IBD. Correspondingly a positive correlation between CCL6 expression in epithelial cells and the extent of epithelial call destruction in ulcerative colitis patients could be observed [65].

\section{CCL20 and CCR6}

CCL20 (LARC) is a recently described chemokine, which together with its cognate receptor CCR6 is considered as an important factor in the uptake of antigens by $M$ cells and subsequent presentation to myeloid dendritic cells [66].

CCL20 is up-regulated in the dome epithelium of Peyer's patches and surface epithelial cells in the colon of active Crohn's disease and ulcerative colitis patients [33]. In DSS-induced colitis CCL-20 is also strongly induced and blockade of CCL20-CCR6 interaction by an anti-CCL20 antibody attenuated gut inflammation [67] and CCR6deficient mice were resistant to the onset of colitis in this experimental model [68].

\section{CCL25 and CCR9}

CCL25 (TECK) is specifically expressed in the small intestine and the thymus. It signals through its receptor CCR9, which is expressed on lymphocytes and IgA secreting plasma cells. The CCL25/CCR9 pathway therefore is regarded as an important mechanism for mucosal homeostasis in the small intestine [66].

It could be shown that CCL25 may be crucially relevant for regional specialization of intestinal immunity, as its expression is limited to the inflamed small intestine in Crohn's disease patients, and it is not expressed in the colon. Furthermore, only lamina propria mononuclear cells in the small intestine express CCR9, again indicating that CCL25 has a key role in the recruitment of effector T cells to the small bowel in Crohn's disease [69]. Expression of CCR9 in mucosal lymphocytes is reduced in Crohn's disease and CCL25 expression is not augmented in the small bowel but rather altered in its distribution pattern (patchy distribution by intestinal crypts) [69, 70]. Remarkably, targeting of CCL25 or CCR9 by blocking antibodies in the SAMP1/Yit mouse model for ileitis was only effective in early stages of the disease, indicating that other mechanisms might perpetuate the inflammatory process in the course of the disease [71]. On the other hand, another experimental ileitis model, the $\mathrm{Tnf}^{\triangle \mathrm{ARE}}$ mouse, demonstrated intestinal inflammation in the small intestine independently of CCL25/CCR9 signaling [72]. Nevertheless a CCR9 antagonist is currently under investigation for the treatment of active Crohn's disease.

\section{CX3CL1 and CX3CR1}

CX3CL1 (fractalkine) is a membrane bound chemokine expressed on vascular endothelial cells, which allows it to act both as a soluble chemokine and a membrane-bound adhesion receptor. The fractalkine receptor CX3CR1 is primarily expressed on monocytes, dendritic cells and lymphocytes. The CX3CL1/CX3CR1 interaction mediates the positioning of dendritic cells to enable them to direct sample gut luminal antigens [73].

The expression of CX3CL1 in the intestinal epithelia and in microvascular cells is significantly up-regulated in Crohn's disease patients, while CX3CR1 can be found in peripheral blood $\mathrm{T}$ cells in IBD patients, correlating with disease activity [74]. These $\mathrm{T}$ lymphocytes bear markers of cytotoxic effector lymphocytes and produce higher amounts of TNF- $\alpha$ and IFN- $\gamma$ [75]. The subsequent treatment of two murine colitis models with a neu- 
tralizing antibody against CX3CL1 showed a striking therapeutic benefit, indicating the potential of targeting the CX3CL1/CX3CR1 axis in the treatment of mucosal inflammation [66]. Interestingly, two polymorphisms of CX3CR1 have recently been reported, of which one seems to have an impact on the Crohn's disease phenotype [76].

\section{CXCL12 and CXCR4}

Recent reports also indicated a possible immunopathogenic role for the chemokine CXCL12 (SDF-1 $\alpha$ ) and its receptor CXCR4. It was originally classified as a constitutive, homeostatic chemokine but increased expression could be demonstrated in intestinal epithelial cells in the inflamed intestine of IBD patients. Moreover, a significant chemotactic effect of CXCL12 was proven on peripheral blood T cells, as well as lamina propria $\mathrm{T}$ cells and this effect could be blocked by specific antibodies against this chemokine or its receptor CXCR4. Therefore the selective manipulation of the CXCL12/CXCR4 axis might also be an attractive target in the management of IBD [77].

\section{Chemokine Decoy Receptor D6}

The decoy receptor D6 internalizes and degrades a broad panel of pro inflammatory chemokines without triggering signal transduction. It therefore binds chemokines which would otherwise activate their conventional chemokine receptors CCR1 to CCR5. This decoy receptor seems to selectively deplete various inflammatory CC chemokines from the extracellular milieu, while CXC and homeostatic chemokines are not recognized [78]. Recently published data indicate that D6 expression is increased in intestinal leukocytes and colonic lymphatic vascular beds in IBD patients and patients with IBD-associated cancer [79]. In functional studies, D6deficient mice revealed a heightened susceptibility to mucosal inflammation in the DSS-model for experimental colitis which was associated with increased levels of several pro-inflammatory chemokines (CCL2, CCL3, CCL5, CXCL1 and CXCL2) and heightened leukocyte recruitment in the inflamed mucosa. Moreover, D6 deletion also led to enhanced tumor formation and increased tumor progression in the AOM-DSS model. These observations indicate that the decoy receptor for inflammatory chemokines D6 is induced during inflammatory reactions to contribute to the resolution of mucosal inflammation through the control of chemokine availability [79]. In this way, D6 offers a novel potential therapeutic strategy for the restoration of mucosal homeostasis in IBD.

\section{Conclusion and Future Prospects}

The entities that comprise IBD are not just simple inflammatory diseases, but instead reflect the intricate interaction of different signaling pathways and cell types of the intestine. The interplay between epithelial and effector immune cells in the gut is commonly believed to be the critical pathogenic mechanism involved in the initiation and perpetuation of the inflammatory reaction, as these cells predominantly participate in the chronic inflammatory response of IBD and secrete pro-inflammatory mediators that facilitate and amplify cell interaction $[2,15]$. Besides an array of cytokines, chemokines have lately also been identified as pivotal mediators in the inflammatory cascade, as their coordinate expression orchestrates the recruitment of leukocyte effector cell populations into the injured tissue, which is a fundamental event in disease progression [11]. Analyzing the functional role of chemokines and their receptors in IBD immunopathogenesis, would enable us to understand if their overexpression is only a secondary phenomenon or whether they play an essential immunopathogenic role in the inflammatory process. As chemokines have a plethora of overlapping functions, it will be critical to identify which of the large numbers of signaling pathways is central to chronic intestinal inflammation and might therefore be specifically targeted for the development of new therapeutic strategies. This therapeutic approach could include agents that specifically inhibit chemokine synthesis or block chemokine binding to receptors on inflammatory cells in order to prevent aberrant leukocyte chemoattraction and diminish the severity of the inflammatory process and thus clinical disease activity. This approach is currently under investigation in a phase I clinical trial with a fully humanized antiCXCL10 antibody.

Nevertheless, blockade of single chemokines or corresponding receptors should be carefully evaluated, as the redundancy of different chemokines for one chemokine receptor and the abundance of different chemokines all mediating overlapping effects is a characteristic hallmark of this protein family. Furthermore, the chemokine network is strongly influenced by other receptor 
systems, such as cytokines or growth receptors which become activated during cell infiltration. Potential safety liabilities of targeting specific chemokines should be considered as well, especially when a chemokine response is entirely blocked thereby compromising the host's immune defense. Therefore, further studies are needed to elucidate the full importance of chemotactic and non-chemotactic roles for chemokines in IBD and the relevant signaling pathways involved. This could enable a novel chemokine-focused approach that would al- low us to specifically intervene in the inflammatory process, based on a more effective and hopefully less toxic therapeutic rationale.

\section{Disclosure Statement}

R. Atreya has a scientific collaboration with Abbott. M.F. Neurath provides expert scientific advice to Giuliani Pharma, Schering-Plough, Essex, Abbott and Pentax.

\section{References}

1 Podolsky DK: Inflammatory bowel disease. N Engl J Med 2002;347:417-429.

2 Neurath MF, Finotto S: Translating inflammatory bowel disease research into clinical medicine. Immunity 2009;31:357-361.

3 Strober W, Fuss I, Mannon P: The fundamental basis of inflammatory bowel disease. J Clin Invest 2007;117:514-521.

4 Abraham C, Cho JH: Inflammatory bowel disease. N Engl J Med 2009;361:2066-2078.

5 Xavier RJ, Podolsky DK: Unravelling the pathogenesis of inflammatory bowel disease. Nature 2007;448:427-434.

6 Garrett WS, Gordon JI, Glimcher LH: Homeostasis and inflammation in the intestine. Cell 2010;140:859-870

7 Powrie F: T cells in inflammatory bowel disease: protective and pathogenic roles. Immunity $1995 ; 3: 171-174$.

8 Neurath MF, Finotto S, Fuss I, Boirivant M, Galle PR, Strober W: Regulation of T-cell apoptosis in inflammatory bowel disease: to die or not to die, that is the mucosal question. Trends Immunol 2001;22:21-26.

9 Sartor RB: Cytokines in intestinal inflammation: pathophysiologic and clinical considerations. Gastroenterology 1998;106:533539.

10 Atreya R, Mudter J, Finotto S, Mullberg J, Jostock T, Wirtz S, Schutz M, Bartsch B, Holtmann M, Becker C, Strand D, Czaja J, Schlaak JF, Lehr HA, Autschbach F, Schurmann G, Nishimoto N, Yoshizaki K, Ito H, Kishimoto T, Galle PR, Rose-John S, Neurath MF: Blockade of interleukin 6 trans signaling suppresses T-cell resistance against apoptosis in chronic intestinal inflammation: evidence in Crohn's disease and experimental colitis in vivo. Nat Med 2000;6:583588.

11 Fina D, Pallone F: What is the role of cytokines and chemokines in IBD? Inflamm Bowel Dis 2008;14(suppl 2):S117-S118.
12 Fuss IJ, Neurath M, Boirivant M, Klein JS, de la Motte C, Strong SA, Fiocchi C, Strober W: Disparate CD4+ lamina propria (LP) lymphokine secretion profiles in inflammatory bowel disease. Crohn's disease LP cells manifest increased secretion of IFN-gamma, whereas ulcerative colitis LP cells manifest increased secretion of IL-5. J Immunol 1996; 157:1261-1270.

13 Harrington LE, Hatton RD, Mangan PR, Turner H, Murphy TL, Murphy KM, Weaver CT: Interleukin 17-producing CD4+ effector $T$ cells develop via a lineage distinct from the Thelper type 1 and 2 lineages. Nat Immunol 2005;6:1123-1132.

14 Fujino S, Andoh A, Bamba S, Ogawa A, Hata K, Araki Y, Bamba T, Fujiyama Y: Increased expression of interleukin 17 in inflammatory bowel disease. Gut 2003;52:65-70.

15 Atreya R, Neurath MF: New therapeutic strategies for treatment of inflammatory bowel disease. Mucosal Immunol 2008; 1: 175-182.

16 Mayer L: Current concept of IBD: etiology and pathogenesis; in Kirsner JB (ed): Inflammatory Bowel Disease, ed 5. Philadelphia, WB Saunders, 2000, pp 280-296.

17 Targan SR, Hanauer SB, van Deventer SJ, Mayer L, Present DH, Braakman T, DeWoody KL, Schaible TF, Rutgeerts PJ: A short-term study of chimeric monoclonal antibody cA2 to tumor necrosis factor alpha for Crohn's disease. Crohn's Disease cA2 Study Group. N Engl J Med 1997;337:10291035.

18 Hanauer SB, Feagan BG, Lichtenstein GR, Mayer LF, Schreiber S, Colombel JF, Rachmilewitz D, Wolf DC, Olson A, Bao W, Rutgeerts P; ACCENT I Study Group: Maintenance infliximab for Crohn's disease: the ACCENT I randomised trial. Lancet 2002; 359:1541-1549.
19 Hanauer SB, Sandborn WJ, Rutgeerts P, Fedorak RN, Lukas M, MacIntosh D, Panaccione R, Wolf D, Pollack P: Human anti-tumor necrosis factor monoclonal antibody (adalimumab) in Crohn's disease: the CLASSIC-I trial. Gastroenterology 2006; 130:323333.

20 Colombel JF, Sandborn WJ, Rutgeerts P, Enns R, Hanauer SB, Panaccione R, Schreiber S, Byczkowski D, Li J, Kent JD, Pollack PF: Adalimumab for maintenance of clinical response and remission in patients with Crohn's disease: the CHARM trial. Gastroenterology 2007;132:52-65.

21 Zimmerman NP, Vongsa RA, Wendt MK, Dwinell MB: Chemokines and chemokine receptors in mucosal homeostasis at the intestinal epithelial barrier in inflammatory bowel disease. Inflamm Bowel Dis 2008;14: 1000-1011.

22 Kucharzik T, Williams IR: Neutrophil migration across the intestinal epithelial barrier - summary of in vitro data and description of a new transgenic mouse model with doxycycline-inducible interleukin-8 expression in intestinal epithelial cells. Pathobiology 2002;70:143-149.

23 Papadakis KA: Chemokines in inflammatory bowel disease. Curr Allergy Asthma Rep 2004;4:83-99.

24 Danese S, Gasbarrini A: Chemokines in inflammatory bowel disease. J Clin Pathol 2005;58:1025-1027.

25 Rollins BJ: Chemokines. Blood 1997;90:909928.

26 Rossi D, Zlotnik A: The biology of chemokines and their receptors. Annu Rev Immunol 2000; 18:217-242.

27 Laing KJ, Secombes CJ: Chemokines. Dev Comp Immunol 2004;28:443-460.

28 MacDermott RP, Sanderson IR, Reinecker HC: The central role of chemokines (chemotactic cytokines) in the immunopathogenesis of ulcerative colitis and Crohn's disease. Inflamm Bowel Dis 1998;4:54-67. 
29 Papadakis KA, Targan SR: The role of chemokines and chemokine receptors in mucosal inflammation. Inflamm Bowel Dis 2000; 6:303-313.

30 Mahida YR, Ceska M, Effenberger F, Kurlak L, Lindley I, Hawkey CJ: Enhanced synthesis of neutrophil-activating peptide-1/interleukin-8 in active ulcerative colitis. Clin Sci (Lond) 1992;82:273-275.

31 Izzo RS, Witkon K, Chen AI, Hadjiyane C, Weinstein MI, Pellecchia C: Neutrophil-activating peptide (interleukin-8) in colonic mucosa from patients with Crohn's disease. Scand J Gastroenterol 1993;28:296-300.

32 Raab Y, Gerdin B, Ahlstedt S, Hallgren R: Neutrophil mucosal involvement is accompanied by enhanced local production of interleukin-8 in ulcerative colitis. Gut 1993;34: 1203-1206.

33 Puleston J, Cooper M, Murch S, Bid K, Makh S, Ashwood P, Bingham AH, Green H, Moss P, Dhillon A, Morris R, Strobel S, Gelinas R, Pounder RE, Platt A: A distinct subset of chemokines dominates the mucosal chemokine response in inflammatory bowel disease. Aliment Pharmacol Ther 2005;21:109-120.

34 Mazzucchelli L, Hauser C, Zgraggen K, Wagner H, Hess M, Laissue JA, Mueller C: Expression of interleukin-8 gene in inflammatory bowel disease is related to the histological grade of active inflammation. Am J Pathol 1994;144:997-1007.

35 Mitsuyama K, Toyunaga A, Sasaki E, Watanabe K: IL-8 as an important chemoattractant for neutrophils in ulcerative colitis and Crohn's disease. Clin Exp Immunol 1994;96: 432-436.

36 Banks C, Bateman A, Payne R, Johnson P, Sheron $\mathrm{N}$ : Chemokine expression in IBD: mucosal chemokine expression is unselectively increased in both ulcerative colitis and Crohn's disease. J Pathol 2003;199:28-35.

37 Nielsen $\mathrm{OH}$, Rudiger N, Gaustadnes $\mathrm{M}$, Horn T: Intestinal interleukin 8 concentration and gene expression in inflammatory bowel disease. Scand J Gastroenterol 1997; 32:1028-1032.

38 Sher ME, D’Angelo AJ, Stein TA, Bailey B, Burns G: Cytokines in Crohn's colitis. Am J Surg 1995;169:133-136.

39 Grimm MC, Elsbury SKO, Parli P, Doe WF: Enhanced expression and production of monocyte chemoattractant protein-1 in inflammatory bowel disease mucosa. J Leukocyte Biol 1996;59:804-812.

40 Arai F, Takahashi T, Furukawa K, Matsushima K, Asakura H: Mucosal expression of interleukin-6 and interleukin-8 messenger RNA in ulcerative colitis and in Crohn's disease. Dig Dis Sci 1998;43:2071-2079.

41 Chapman RW, Phillips JE, Hipkin RW, Curran AK, Lundell D, Fine JS: CXCR2 antagonists for the treatment of pulmonary disease. Pharmacol Ther 2009;121:55-68.
42 Wuyts A, Proost P, Lenaerts JP, Ben-Baruch A, Van Damme J, Wang JM: Differential usage of the CXC chemokine receptors 1 and 2 by interleukin-8, granulocyte chemotactic protein-2 and epithelial-cell-derived neutrophil attractant-78. Eur J Biochem 1998;255 67-73.

43 Bonecchi R, Bianchi G, Bordignon PP D’Ambrosio D, Lang R, Borsatti A, Sozzani S, Allavena P, Gray PA, Mantovani A, Sinigaglia F: Differential expression of chemokine receptors and chemotactic responsiveness of type $1 \mathrm{~T}$ helper cells (Th1s) and Th2s. J Exp Med 1998;187:129-134.

44 Sasaki S, Yoneyama H, Suzuki K, Suriki H, Aiba T, Watanabe S, Kawauchi Y, Kawachi H, Shimizu F, Matsushima K, Asakura H, Narumi S: Blockade of CXCL10 protects mice from acute colitis and enhances crypt cell survival. Eur J Immunol 2002;32:3197-3205.

45 Taub DD, Sayers TJ, Carter CR, Ortaldo JR: Alpha and beta chemokines induce NK cell migration and enhance NK-mediated cytolysis. J Immunol 1995;155:3877-3888.

46 Yuan YH, ten Hove T, The FO, Slors JF, van Deventer SJ, te Velde AA: Chemokine receptor CXCR3 expression in inflammatory bowel disease. Inflamm Bowel Dis 2001;7: 281-286.

47 Singh UP, Singh S, Taub DD, Lillard JW Jr: Inhibition of IFN-gamma-inducible protein-10 abrogates colitis in IL-10-/- mice. J Immunol 2003;171:1401-1406.

48 Uguccioni M, Gionchetti P, Robbiani DF, Rizzello F, Peruzzo S, Campieri M, Baggiolini M: Increased expression of IP-10, IL-8, MCP-1, and MCP-3 in ulcerative colitis. Am J Pathol 1999;155:331-336.

49 Singh UP, Venkataraman C, Singh R, Lillard JW Jr: CXCR3 axis: role in inflammatory bowel disease and its therapeutic implication. Endocr Metab Immune Disord Drug Targets 2007;7:111-123.

50 Sasaki S, Yoneyama H, Suzuki K, Suriki H, Aiba T, Watanabe S, Kawauchi Y, Kawachi H, Shimizu F, Matsushima K, Asakura H, Narumi S: Blockade of CXCL10 protects mice from acute colitis and enhances crypt cell survival. Eur J Immunol 2002;32:3197-3205.

51 Farooq SM, Stillie R, Svensson M, Svanborg C, Strieter RM, Stadnyk AW: Therapeutic effect of blocking CXCR2 on neutrophil recruitment and dextran sodium sulfate-induced colitis. J Pharmacol Exp Ther 2009; 329:123-129.

52 Matsushima K, Larsen CG, DuBois GC, Oppenheim JJ: Purification and characterization of a novel monocyte chemotactic and activating factor produced by a human myelomonocytic cell line. J Exp Med 1989;169: 1485-1490.

53 Mazzucchelli L, Hauser C, Zgraggen K, Wagner HE, Hess MW, Laissue JA, Mueller C: Differential in situ expression of the genes encoding the chemokines MCP-1 and RANTES in human inflammatory bowel disease. J Pathol 1996;178:201-206.
54 Reinecker C, Loh EY, Ringler DJ, Mehta A, Rombeau JL, MacDermott RP: Monocytechemoattractant protein 1 gene expression in intestinal epithelial cells and inflammatory bowel disease mucosa. Gastroenterology $1995 ; 108: 40-50$.

55 Imai T, Hieshima K, Haskell C, Baba M, Nagira M, Nishimura M, Kakizaki M, Takagi $\mathrm{S}$, Nomiyama H, Schall TJ, Yoshie O: Identification and molecular characterization of fractalkine receptor CX3CR1, which mediates both leukocyte migration and adhesion. Cell 1997;91:521-530.

56 Andreas PG, Beck PL, Mizoguchi E, Mizoguchi A, Bhan AK, Dawson T, Kuziel WA, Maeda N, MacDermott RP, Podolsky DK, Reinecker HC: Mice with a selective deletion of the CC chemokine receptors 5 or 2 are protected from dextran sodium sulfate-mediated colitis: lack of CC chemokine receptor 5 expression results in a NK1.1+ lymphocyteassociated Th2-type immune response in the intestine. J Immunol 2000;164:6303-6312.

57 Tokuyama H, Ueha S, Kurachi M, Matsushima K, Moriyasu F, Blumberg RS, Kakimi K: The simultaneous blockade of chemokine receptors CCR2, CCR5 and CXCR 3 by a non-peptide chemokine receptor antagonist protects mice from dextran sodium sulphate mediated colitis. Int Immunol 2005; 17: 1023-1034.

58 Popivanova BK, Kostadinova FI, Furuichi K, Shamekh MM, Kondo T, Wada T, Egashira $\mathrm{K}$, Mukaida N: Blockade of a chemokine, CCL2, reduces chronic colitis-associated carcinogenesis in mice. Cancer Res 2009;69: 7884-7892.

59 Maharshak N, Hart G, Ron E, Zelman E, Sagiv A, Arber N, Brazowski E, Margalit R, Elinav E, Shachar I: CCL2 (pM levels) as a therapeutic agent in inflammatory bowel disease models in mice. Inflamm Bowel Dis 2010, E-pub ahead of print.

60 Ajuebor MN, Hogaboam CM, Kunkel SL, Proudfoot AE, Wallace JL: The chemokine RANTES is a crucial mediator of the progression from acute to chronic colitis in the rat. J Immunol 2001;166:552-558.

61 Kunkel EJ, Boisvert J, Murphy K, Vierra MA, Genovese MC, Wardlaw AJ, Greenberg HB, Hodge MR, Wu L, Butcher EC, Campbell JJ: Expression of the chemokine receptors CCR4, CCR5, and CXCR 3 by human tissueinfiltrating lymphocytes. Am J Pathol 2002; 160:347-355.

62 Oki M, Ohtani H, Kinouchi Y, Sato E, Nakamura S, Matsumoto T, Nagura H, Yoshie O, Shimosegawa T: Accumulation of CCR5+ $\mathrm{T}$ cells around RANTES+ granulomas in Crohn's disease: a pivotal site of Th1-shifted immune response? Lab Invest 2005;85:137145.

63 Kang SG, Lim HW, Andrisani OM, Broxmeyer HE, Kim CH: Vitamin A metabolites induce gut-homing FoxP3-regulatory T cells. J Immunol 2007;179:3724-3733. 
64 Kang SG, Piniecki RJ, HogenEsch H, Lim HW, Wiebke E, Braun SE, Matsumoto S, Kim CH: Identification of a chemokine network that recruits FoxP3 regulatory $\mathrm{T}$ cells into chronically inflamed intestine. Gastroenterology 2007;132:966-981.

65 Wedemeyer J, Lorentz A, Göke M, Meier PN, Flemming P, Dahinden CA, Manns MP, Bischoff SC: Enhanced production of monocyte chemotactic protein 3 in inflammatory bowel disease mucosa. Gut 1999;44:629-635.

66 Nishimura M, Kuboi Y, Muramoto K, Kawano T, Imai T: Chemokines as novel therapeutic targets for inflammatory bowel disease. Ann NY Acad Sci 2009;1173:350-356.

67 Teramoto K, Miura S, Tsuzuki Y, Hokari R, Watanabe C, Inamura T, Ogawa T, Hosoe N, Nagata H, Ishii H, Hibi T: Increased lymphocyte trafficking to colonic microvessels is dependent on MAdCAM-1 and C-C chemokine mLARC/CCL20 in DSS-induced mice colitis. Clin Exp Immunol 2005;139:421428.

68 Varona R, Cadenas V, Flores J, Martínez-A C, Márquez G: CCR6 has a non-redundant role in the development of inflammatory bowel disease. Eur J Immunol 2003;33:29372946.

69 Papadakis KA, Prehn J, Moreno ST, Cheng L, Kouroumalis EA, Deem R, Breaverman T, Ponath PD, Andrew DP, Green PH, Hodge MR, Binder SW, Targan SR: CCR9-positive lymphocytes and thymus-expressed chemokine distinguish small bowel from colonic Crohn's disease. Gastroenterology 2001;121: 246-254.
70 Eksteen B, Liaskou E, Adams DH: Lymphocyte homing and its role in the pathogenesis of IBD. Inflamm Bowel Dis 2008; 14:12981312.

71 Rivera-Nieves J, Ho J, Bamias G, vashkina N, Ley K, Oppermann M, Cominelli F: Antibody blockade of CCL25/CCR9 ameliorates early but not late chronic murine ileitis. Gastroenterology 2006;131:1518-1529.

72 Apostolaki M, Manoloukos M, Roulis M Wurbel MA, Müller W, Papadakis KA, Kontoyiannis DL, Malissen B, Kollias G: Role of beta7 integrin and the chemokine/chemokine receptor pair CCL25/CCR9 in modeled TNF-dependent Crohn's disease. Gastroenterology 2008;134:2025-2035.

73 Niess JH, Brand S, Gu X, Landsman L, Jung S, McCormick BA, Vyas JM, Boes M, Ploegh HL, Fox JG, Littman DR, Reinecker HC: CX3CR1-mediated dendritic cell access to the intestinal lumen and bacterial clearance. Science 2005;307:254-258.

74 Sans M, Danese S, de la Motte C, de Souza HS, Rivera-Reyes BM, West GA, Phillips M, Katz JA, Fiocchi C: Enhanced recruitment of CX3CR1+ T cells by mucosal endothelial cell-derived fractalkine in inflammatory bowel disease. Gastroenterology 2007;132: 139-153.

75 Kobayashi T, Okamoto S, Iwakami Y, Nakazawa A, Hisamatsu T, Chinen H, Kamada N, Imai T, Goto H, Hibi T: Exclusive increase of CX3CR1+CD28-CD4+ T cells in inflammatory bowel disease and their recruitment as intraepithelial lymphocytes. Inflamm Bowel Dis 2007;13:837-846.
76 Brand S, Hofbauer K, Dambacher J, Schnitzler F, Staudinger T, Pfennig S, Seiderer J, Tillack C, Konrad A, Göke B, Ochsenkühn T, Lohse P: Increased expression of the chemokine fractalkine in Crohn's disease and association of the fractalkine receptor T280M polymorphism with a fibrostenosing disease phenotype. Am J Gastroenterol 2006;101: 99-106.

77 Dotan I, Werner L, Vigodman S, Weiss S, Brazowski E, Maharshak N, Chen O, Tulchinsky H, Halpern Z, Guzner-Gur H: CXCL12 is a constitutive and inflammatory chemokine in the intestinal immune system. Inflamm Bowel Dis 2010;16:583-592.

78 Locati M, Torre YM, Galliera E, Bonecchi R, Bodduluri H, Vago G, Vecchi A, Mantovani A: Silent chemoattractant receptors: D6 as a decoy and scavenger receptor for inflammatory CC chemokines. Cytokine Growth Factor Rev 2005;16:679-686.

79 Vetrano S, Borroni EM, Sarukhan A, Savino B, Bonecchi R, Correale C, Arena V, Fantini M, Roncalli M, Malesci A, Mantovani A, Locati M, Danese S: The lymphatic system controls intestinal inflammation and inflammation-associated colon cancer through the chemokine decoy receptor D6. Gut 2010;59: 197-206. 